\title{
Suplementação com Sal Mineral Proteinado para Bovinos de Corte, em Crescimento e Terminação, Mantidos em Pastagem de Grama Estrela Roxa (Cynodon plectostachyrus Pilger), no Inverno ${ }^{1}$
}

\section{Fernanda Barros Moreira ${ }^{2}$, Ivanor Nunes do Prado ${ }^{3}$, Ulysses Cecato ${ }^{3}$, Fábio Yoshimi Wada ${ }^{4}$, Willian Gonçalves do Nascimento ${ }^{5}$, Nilson Evelázio de Souza ${ }^{6}$}

\begin{abstract}
RESUMO - Os objetivos deste trabalho foram estudar o efeito da suplementação com sal mineral proteinado, em comparação ao sal mineral, sobre o desempenho de novilhos em crescimento e terminação e avaliar a composição, disponibilidade e digestibilidade in vitro da forragem, no inverno. Foram utilizados 74 novilhos, sendo 37 com peso inicial médio de $266 \mathrm{~kg}$ e $37 \mathrm{com} 377 \mathrm{~kg}$. No início do período de baixa produção forrageira (maio), os dois grupos (crescimento e terminação) foram separados em dois tratamentos: suplementação mineral (SMI) ou suplementação com sal mineral proteinado (SMP). Foram utilizados quatro piquetes de grama estrela roxa (Cyonodon plectostachyrus Pilger), em pastejo contínuo. A avaliação da disponibilidade e qualidade da forragem foi realizada a cada 28 dias. O consumo médio do sal mineral e sal mineral proteinado foi de 42 e $184 \mathrm{~g} / \mathrm{animal} / \mathrm{dia}$ para os animais em crescimento e 57 e 281 g/animal/dia para os animais em terminação. Não houve diferença no GMD entre SMI e SMP, tanto para os animais em crescimento $(0,17 \mathrm{~kg} /$ dia e $0,16 \mathrm{~kg} / \mathrm{dia})$, como para os animais em terminação $(0,01 \mathrm{~kg} / \mathrm{dia}$ e $0,02 \mathrm{~kg} / \mathrm{dia})$. Todavia, o GMD para os animais em crescimento $(0,17 \mathrm{~kg} / \mathrm{dia})$ foi maior em relação aos animais em terminação $(0,01 \mathrm{~kg} / \mathrm{dia})$. A disponibilidade e qualidade da forragem foram semelhantes entre os tratamentos, com valores médios de $3643 \mathrm{~kg}$ de matéria seca/ha, $2041 \mathrm{~kg}$ de matéria seca verde/ha e $285 \mathrm{~kg}$ de folhas/ ha. A proporção de folhas foi baixa (7\%) para todos os tratamentos, em decorrência do alto teor de material morto (44\%). A forragem apresentou, em média, 4,5\% PB, 79,9\% FDN, 51,5\% FDA e 44,0\% de DIVMS.
\end{abstract}

Palavras-chave: bovinos de corte, ganho de peso, suplementação protéica, uréia

\section{Protein Mineral Salt Supplements for Growing and Finishing Beef Cattle in Star Grass (Cynodon plectostachyrus Pilger), in the Winter}

\begin{abstract}
This work was carried out to study the effect of protein and mineral salt supplements in comparison to mineral salt on performance of growing and finishing steers, and to evaluate the availability, chemical composition andin vitro digestibility of forage during the winter. Seventy four steers were used, 37 with $266 \mathrm{~kg}$ of initial body weight and 37 with $377 \mathrm{~kg}$ of initial body weight. At the onset of the fall grass production period in May both animal groups (growing and finishing) were divided into two treatments: mineral supplement (MIS) or protein and mineral supplement (PMS). Four pastures of violet star grass forage (Cynodon plectostachyus Pilger) were used, in continuous grazing. The quality and availability evaluation of forage were estimated every 28 days. The average intake of mineral salt and protein mineral salt were 42 and $184 \mathrm{~g}$ per animal a day for growing animals and 57 and $281 \mathrm{~g}$ per animal a day for finishing animals. There was no difference in average daily gain between treatments, either for growing animals $(0.17 \mathrm{~kg}$ a day and 0.16 $\mathrm{kg}$ a day) and finishing animals $(0.01 \mathrm{~kg}$ a day and $0.02 \mathrm{~kg}$ a day). However, the average daily gain for growing animals was superior ( 0.17 $\mathrm{kg}$ a day) when compared with finishing animals ( $0.01 \mathrm{~kg}$ a day). The quality and availability of the pasture were similar to the different treatments, with average levels of $3643 \mathrm{~kg}$ of dry matter/ha, $2041 \mathrm{~kg}$ of green dry matter/ha, and $285 \mathrm{~kg}$ of leaves/ha. The leaf proportion was small (7\%) for all treatments in function of the high dead material (44\%) proportion. The pasture had in average $4.5 \% \mathrm{CP}, 1.8 \%$ DCP, $79.9 \%$ NDF, $51.5 \%$ ADF, and 44.0\% IVDMD.
\end{abstract}

Key Words: beef steers, protein supplementation, urea, weight gain

\footnotetext{
${ }_{1}^{1}$ Parte da Tese de Doutorado da primeira autora, Universidade Estadual de Maringá, Maringá, PR.

2 Médica veterinária. E.mai: fbmoreira@sercomtel.com.br

${ }^{3}$ Professor do Departamento de Zootecnia da Universidade Estadual de Maringá. Av. Colombo, 5790, Maringá, PR, pesquisador I do CNPq E.mail: inprado@uem.br; ucecato@uem.br

4 Mestrando em Produção Animal pela Universidade Estadual de Maringá. E.mail: fyw@ig.com.br

${ }^{5}$ Doutorando em Produção Animal pela Universidade Estadual de Maringá. E.mail: williangnascimento@ig.com.br

${ }^{6}$ Professor do Departamento de Química da Universidade Estadual de Maringá, pesquisador do CNPq.E.mail: nesouza@uem.br
} 


\section{Introdução}

A produção de carne bovina brasileira caracteriza-se quase que exclusivamente em sistemas pastoris. Segundo dados da FNP (2001), do total do rebanho bovino brasileiro (161 milhões de animais), $20 \%$ são abatidos anualmente (32 milhões de animais), sendo que deste total, aproximadamente 30 milhões são terminados em pastagens, ou seja 93,75\% do número de animais abatidos. Os demais animais são terminados em sistemas de confinamento ou semi-confinamento. Estes dados demonstram a importância dos sistemas de produção em pastagens na pecuária nacional.

As pastagens tropicais e subtropicais apresentam períodos de alta produção forrageira (estação de primavera e verão) e períodos de baixa produção forrageira (estação de outono e inverno). Algumas práticas de manejo têm sido adotadas para minimizar as perdas ocorridas durante o período de baixa produção forrageira, como por exemplo, a suplementação protéica ou energética (Reis et al., 1997; Grandini, 2001; Moreira et al. 2001a), suplementação com volumosos (Morais, 1999; Nussio et al., 2001) ou a utilização de forrageiras de inverno (Cecato et al., 1998; Moraes \& Lustosa, 1999; Moreira et al., 2001b). Dentre estas, a suplementação em pastagem com minerais e concentrados (protéicos e energéticos) tem apresentado melhor desempenho animal quando comparada apenas à suplementação mineral (Grandini, 2001). Euclides et al. (2001) observaram melhor desempenho de bovinos mantidos em pastagens suplementados com $0,8 \%$ do peso vivo com concentrado protéico e energético em comparação ao sal mineral. No entanto, este melhor desempenho não foi suficiente para compensar os custos adicionais da suplementação. Por outro lado, a suplementação com sal mineral proteinado, em níveis de até $0,2 \%$ do peso vivo, é uma alternativa de menor custo, devido ao consumo reduzido do suplemento, sendo capaz de minimizar as perdas ocorridas durante o período seco (Moreira et al., 2001a).

A finalidade do sal mineral proteinado é fornecer nitrogênio degradável no rúmen para atender a exigência mínima de $7 \%$ de proteína bruta no rúmen (Van Soest, 1994), para assim melhorar a digestibilidade da forragem (Heldt et al., 1999) e, conseqüentemente, proporcionar melhor desempenho para animais mantidos em pastagens no período de baixa disponibilidade de forragem (Euclides et al., 1998).
O objetivo deste trabalho foi avaliar o efeito da suplementação com sal mineral proteinado sobre o desempenho de bovinos de corte, em crescimento e terminação, assim como avaliar a qualidade e a disponibilidade da forragem e o ganho de peso vivo por hectare em pastagem de estrela roxa no inverno.

\section{Material e Métodos}

O experimento foi conduzido na Fazenda Ibicatu, localizada no município de Centenário do Sul, região norte do Paraná. O solo da região é do tipo Latossolo vermelho escuro, textura média e o clima é caracterizado por subtropical úmido mesotérmico, conforme descrito pela SEAB (1994).

Foram utilizados 74 novilhos, sendo 37 com peso inicial médio de $266 \mathrm{~kg}$ e $37 \mathrm{com}$ peso inicial médio de $377 \mathrm{~kg}$. Os animais mais jovens eram $1 / 2$ Nelore $\mathrm{x} 1 / 2$ Girolando e os animais mais pesados, eram: 17 da raça Nelore, 12 1/2 Nelore x $1 / 2$ Girolando e 8 1/2 Nelore $\mathrm{x} 1 / 2$ Limousin. Os animais foram distribuídos de forma homogêna nos diferentes tratamentos.

Os animais foram mantidos em pastagem de grama estrela roxa (Cynodon plectostachyrus Pilger.), recebendo apenas suplementação mineral antes do início do experimento. Quinze dias do início do experimento, os animais foram vacinados contra febre aftosa e desverminados com vermífugo à base de albendazol. Após 60 dias de experimento, os animais foram novamente desverminados com $\mathrm{o}$ mesmo vermífugo. $\mathrm{O}$ controle da mosca do chifre foi realizado com uso de inseticidas à base de cipermetrina e organofosforados, em função das necessidades.

Os animais foram identificados e separados ao acaso para os diferentes tratamentos: 1 . suplementação mineral (SMI); 2. suplementação mineral + protéica (SMP). Como suplementos foram utilizados o farelo de soja, milho triturado, uréia, vitamina A, D e E e suplemento mineral de forma a fornecer $40 \%$ de proteína bruta e $1500 \mathrm{kcal}$ de energia metabolizável $/ \mathrm{kg}$ de MS do suplemento. O suplemento mineral apresentava, para cada $\mathrm{kg}$ de suplemento: $15 \mathrm{~g} \mathrm{P}, 56 \mathrm{~g} \mathrm{Ca}, 15 \mathrm{~g} \mathrm{Mg}, 16 \mathrm{~g} \mathrm{~S}, 56 \mathrm{~g} \mathrm{Na}$, $2500 \mathrm{mg} \mathrm{Zn}, 650 \mathrm{mg} \mathrm{Cu}, 1250 \mathrm{mg} \mathrm{Mn}, 500 \mathrm{mg} \mathrm{Fe}, 25 \mathrm{mg}$ Co, 40 mg I, 15 mg Se e 150 mg Fl. A distribuição do sal mineral protéico foi realizada três vezes por semana. O consumo dos suplementos foi controlado pela presença do cloreto de sódio no suplemento.

Os animais foram pesados no início do experimento e a cada 28 dias, totalizando cinco períodos de 
28 dias. O experimento foi conduzido entre os meses de maio a outubro do ano 2000.

Foram utilizados dois piquetes com área de 20 ha cada, para os animais em terminação e 2 piquetes com área de 17 ha cada para os animais em crescimento. Cada piquete era formado com pastagem cultivada de grama estrela roxa (Cyonodon plectostachyrus Pilger.). A cada 14 dias, os animais foram trocados de piquete de forma que a cada pesagem os animais dos dois tratamentos passavam pelos dois piquetes experimentais. Nos piquetes estavam localizados bebedouros com capacidade de 4000 L e cochos cobertos com comprimento de $5 \mathrm{~m}$ linear.

Os piquetes foram mantidos em pastejo contínuo, com taxa de lotação de 0,67 UA/ha para os animais em crescimento, e, para os animais em terminação, a taxa de lotação foi de $0,78 \mathrm{UA} / \mathrm{ha}$. Foi utilizada esta taxa de lotação para que a disponibilidade de forragem fosse mantida acima de $2000 \mathrm{~kg}$ de matéria seca/ ha durante todo o período experimental.

Para estimar a disponibilidade da forragem foram coletadas 9 amostras de $0,25 \mathrm{~m}^{2}$ por piquete, a cada 28 dias, conforme técnica descrita por Houlderbaun \& Sollenberg (1992). Estas amostras foram separadas em duas porções, sendo que uma delas foi separada em folha, colmo e material morto. Essas porções, assim como a porção de planta inteira, foram secas em estufa a $55^{\circ} \mathrm{C}$ por $72 \mathrm{~h}$ e moídas em moinho tipo faca com peneira de $1 \mathrm{~mm}$, para análises posteriores. A disponibilidade de folhas, colmo e material morto por piquete foi avaliada a cada 28 dias.

Para avaliar a composição química da forragem, foram determinados os teores de matéria seca (MS), matéria orgânica $(\mathrm{MO})$, proteína bruta $(\mathrm{PB})$, proteína bruta digestível (PBD), fibra em detergente neutro (FDN) e fibra detergente ácido (FDA), conforme descrito por Silva (1990). Os teores de PBD foram obtidos subtraindo-se a proteína insolúvel em detergente ácido do teor de PB, conforme metodologia descrita por Sniffen et al. (1992).

A digestibilidade in vitro da MS (DIVMS) foi determinada pela metodologia de Tilley \& Terry (1963), adaptada para o uso do rúmen artificial, desenvolvida por ANKOM®, conforme descrito por Holden (1999). O teor de NDT foi considerado igual à digestibilidade in vitro da matéria orgânica, sendo esta estimada pela fórmula: DIVMO = - 0,664 + 1,032DIVMS (Moore et al., 1999). O consumo da forragem foi estimado através da fórmula: Consumo $=\mathrm{PJ}^{0,75}\left(0,1493\right.$ Elm $\left.-0,046 \mathrm{Elm}^{2}-0,0196\right)$, sendo PJ o peso em jejum e Elm a energia líquida de mantença da forragem estimada a partir do NDT, conforme descrito pelo NRC (1996). Para estimativa do consumo de forragem, foi utilizado o modelo descrito pelo NRC (1996) como o mais adequado para predizer o consumo de dietas baseadas em forragem.

A análise estatística foi realizada utilizando-se do Sistema de Análises Estatísticas e Genéticas (SAEG). As análises para animais em crescimento e terminação foram realizadas separadamente. Para os animais em crescimento, foi utilizado o modelo: Yij $=\mu+\mathrm{Ti}+$ eij e para os animais em terminação, o modelo: $Y i j=\mu+T i+B j+e i j$, em que:

Yij é variável observada; $\mu$, constante geral; Ti, efeito do tratamento; $\mathrm{Bj}$, efeito da raça; eij, erro aleatório associado a cada observação.

\section{Resultados e Discussão}

Não foi observada diferença $(\mathrm{P}>0,05)$ para peso vivo médio final (PVF) e ganho médio diário (GMD) para os tratamentos SMI e SMP, tanto para os animais em crescimento como para os animais em terminação (Tabela 1). Todavia, deve ser destacado o baixo GMD observado para os animais dos dois tratamentos e para as duas categorias animais. Este baixo GMD poderia estar associado ao baixo consumo estimado de forragem no período, assim como ao baixo consumo de suplemento protéico $(0,07 \%$ do peso vivo) e ao valor nutritivo da forragem (pequena disponibilidade de folhas, baixo teor de PB e baixa digestibilidade da MS).

Moreira et al. (2001a) observaram melhor ganho médio diário $(0,15 \mathrm{~kg} / \mathrm{animal} / \mathrm{dia})$ para animais suplementados com sal mineral proteinado em nível de ingestão do suplemento de $0,10 \%$ do peso vivo. Neste estudo, não foi observada diferença no ganho médio diário quando a ingestão do suplemento protéico era de $0,07 \%$ do peso vivo $(0,06 \mathrm{~kg} / \mathrm{animal} / \mathrm{dia})$ e para os animais suplementados com sal mineral $(0,05 \mathrm{~kg} /$ animal/dia).

Zanetti et al. (2000) observaram GMD de $0,36 \mathrm{~kg} /$ animal/dia para animais suplementados com sal proteinado e perda média diária de $0,10 \mathrm{~kg}$ para animais suplementados apenas com sal mineral. No entanto, o consumo médio do suplemento protéico foi de $0,65 \mathrm{~kg} / \mathrm{animal} / \mathrm{dia}$, valor este superior ao observado neste experimento.

O GMD $(0,17 \mathrm{~kg})$ para os animais em crescimento foi superior ao GMD $(0,02 \mathrm{~kg})$ para os animais em 
Tabela 1 - Médias e coeficiente de variação (CV\%) para peso vivo inicial (PVI), peso vivo final (PVF), ingestão média diária do suplemento (IDS), estimativa de ingestão média diária da forragem (IDF), ganho médio diário (GMD) e ganho de peso vivo por hectare (GPV/ha) para os diferentes tratamentos

Table 1 - Means and coefficient of variation for initial body weight (IBW), final body weight (FBW), average daily supplement intake (DSI), estimated average forage daily intake (DFI), average daily gain (ADG) and body weight gain per hectare (BWG/ ha) for different treatments

\begin{tabular}{|c|c|c|c|c|c|c|}
\hline \multirow[t]{2}{*}{$\begin{array}{l}\text { Parâmetros } \\
\text { Parameters }\end{array}$} & \multicolumn{3}{|c|}{$\begin{array}{c}\text { Novilhos em crescimento } \\
\text { Growing steers }\end{array}$} & \multicolumn{3}{|c|}{$\begin{array}{c}\text { Novilhos em terminação } \\
\text { Finishing steers }\end{array}$} \\
\hline & $\mathrm{SMI}^{1}$ & $\mathrm{SMP}^{2}$ & $\mathrm{CV}$ & SMI $^{1}$ & $\mathrm{SMP}^{2}$ & $\mathrm{CV}$ \\
\hline $\begin{array}{l}\text { PVI }(\mathrm{kg}) \\
I B W(\mathrm{~kg})\end{array}$ & 266 & 266 & 15,38 & 377 & 377 & 7,68 \\
\hline $\begin{array}{l}\text { PVF }(\mathrm{kg}) \\
F B W(k g)\end{array}$ & 291 & 289 & 11,63 & 379 & 380 & 7,11 \\
\hline $\begin{array}{l}\text { IDS (g/animal/dia) } \\
\text { DSI (g/animal/day) }\end{array}$ & 42 & 184 & - & 57 & 281 & - \\
\hline $\begin{array}{l}\text { IDF }(\% \text { do PV) } \\
D F I(\% \text { of } B W)\end{array}$ & 1,55 & 1,65 & - & 1,53 & 1,48 & - \\
\hline $\begin{array}{l}\text { GMD (kg/dia) } \\
A D G(k g / \text { day })\end{array}$ & 0,17 & 0,16 & 78,82 & 0,01 & 0,02 & 2,96 \\
\hline $\begin{array}{l}\text { GPV/ha (kg) } \\
B W G / h a(k g)\end{array}$ & 27,34 & 25,14 & - & 1,92 & 2,89 & - \\
\hline
\end{tabular}

1SMI: sal mineral; ${ }^{2} \mathrm{SMP}$ : sal mineral proteinado.

${ }^{1}$ SMI: mineral salt; ${ }^{2}$ SMP: protein mineral salt.

terminação. Isso ocorreu uma vez que a exigência em energia líquida de mantença é inferior para os animais com peso médio $280 \mathrm{~kg}$, com valores de 4,74 Mcal/ dia, quando comparado a animais de $380 \mathrm{~kg}$, com valores de 5,96 Mcal/dia (NRC, 1996). Como a disponibilidade e qualidade da forragem para os animais em crescimento e terminação foram semelhantes (Tabelas 2 e 3), o maior GMD para os animais em crescimento é justificado pela menor exigência em energia líquida de mantença.

O consumo médio diário de MS (1,55\% do peso vivo) estimado da forragem foi semelhante para os animais dos tratamentos SMI e SMP, assim como para os animais em crescimento e terminação. Para ambas as categorias animais, o consumo de MS estimado foi baixo (NRC, 1996). A reduzida ingestão de MS determinou, por conseqüência, baixa ingestão de $\mathrm{PB}$ e EB. A pouca ingestão de nutrientes é decorrente do pobre valor nutritivo da forragem (Tabela 4). Desta forma, a baixa ingestão da forragem associada à escassa qualidade nutricional da mesma determinou o pequeno desempenho animal observado durante todo o período experimental.

O ganho de peso vivo por hectare (GPV/ha), observado para os animais dos tratamentos SMI e SMP, foi semelhante $(14,3 \mathrm{~kg})$, independentemente da categoria animal. No entanto, o GPV/ha para os animais em crescimento $(26,2 \mathrm{~kg})$ foi maior do que aquele observado para os animais em terminação $(2,4$ $\mathrm{kg}$ ). Isto se deve ao maior GMD observado para os animais em crescimento quando comparado aos animais em terminação (Tabela 1). Os valores de GPV/ ha observados foram semelhantes aos descritos pela FNP (2001), para um sistema extensivo de produção em pastagens, no período de baixa produção forrageira. Estes baixos ganhos em peso determinam idades avançadas de abate dos animais nas regiões menos desenvolvidas no mundo.

A disponibilidade de matéria seca total (folha + colmo + material morto - MST), matéria seca verde (folha + colmo - MSV) e de folhas por hectare foi semelhante para os tratamentos SMI e SMP, assim como para os animais em crescimento e terminação (Tabela 2). Independentemente de tratamento e da categoria animal, a disponibilidade média de MST (3643 kg) esteve acima dos $2000 \mathrm{~kg} / \mathrm{ha}$. Este valor foi estipulado por Minson (1990) como sendo o mínimo para que não ocasionasse redução no consumo da pastagem. Por outro lado, a disponibilidade de MSV, independente de tratamento e categoria animal, esteve próximo ao valor crítico de $2000 \mathrm{~kg} / \mathrm{ha}$. Esta grande diferença observada entre a disponibilidade de MST e MSV ocorreu em função da alta porcentagem de material morto presente na pastagem. O material morto representou, em média, $44 \%$ da MS. Assim, a elevada porcentagem de material morto 
Tabela 2 - Disponibilidade de matéria seca total (MST), matéria seca verde (MSV) e de folhas por hectare e proporção de folha, colmo e matéria morta na pastagem para os diferentes tratamentos

Table 2 - Total dry matter (TDM), green dry matter (GDM) and leaves availability per hectare and leaf, steam and dead material proportion in grassland for the different animals groups and treatments

\begin{tabular}{|c|c|c|c|c|}
\hline & \multicolumn{2}{|c|}{$\begin{array}{l}\text { Novilhos em } \\
\text { crescimento } \\
\text { Growing steers } \\
\end{array}$} & \multicolumn{2}{|c|}{$\begin{array}{l}\text { Novilhos em } \\
\text { terminação } \\
\text { Finishing steers }\end{array}$} \\
\hline & $\mathrm{SMI}^{1}$ & $\mathrm{SMP}^{2}$ & $\mathrm{SMI}^{1}$ & $\mathrm{SMP}^{2}$ \\
\hline $\operatorname{MST}(\mathrm{kg} / \mathrm{ha})$ & 3507 & 3533 & 3803 & 3730 \\
\hline $\begin{array}{l}\text { TDM (kg/ha) } \\
\operatorname{MSV~(kg/ha)} \\
G D M(k g / h a)\end{array}$ & 1867 & 1940 & 2194 & 2165 \\
\hline $\begin{array}{l}\text { Folhas }(\mathrm{kg} / \mathrm{ha}) \\
\text { Leaves }(\mathrm{kg} / \mathrm{ha})\end{array}$ & 310 & 305 & 279 & 248 \\
\hline $\begin{array}{l}\text { Folhas }(\%) \\
\text { Leaves }(\%)\end{array}$ & 8 & 9 & 6 & 5 \\
\hline $\begin{array}{l}\text { Colmo }(\%) \\
\text { Steam }(\%)\end{array}$ & 45 & 46 & 51 & 53 \\
\hline $\begin{array}{l}\text { Material morto }(\%) \\
\text { Dead material }(\%)\end{array}$ & 47 & 45 & 43 & 42 \\
\hline
\end{tabular}

determinou o baixo valor nutritivo da forragem analisada (Tabela 3). O baixo valor nutritivo da forragem e a disponibilidade limitada de matéria seca verde determinaram o baixo desempenho animal.

Os teores médios de proteína bruta $(\mathrm{PB})$ e proteína bruta digestível (PBD) da forragem total foram semelhantes e baixos para os tratamentos SMI $(4,49$ e $1,78 \% / \mathrm{MS})$ e SMP $(4,48$ e $1,82 \% / \mathrm{MS})$, respectivamente (Tabela 3). Valadares Filho (2000) relatou para a grama estrela, com idade entre 46 a 135 dias, teores de PB de 5,53\%. Este valor é superior ao obtido neste experimento, possivelmente devido à baixa proporção de folhas ocorridas na pastagem. Por outro lado, os teores de FDN e FDA não apresentaram teores diferentes entre tratamentos, com teores elevados, da ordem de $79,9 \%$ e $51,5 \% / \mathrm{MS}$, respectivamente. Os valores de FDA foram superiores a $40 \%$, sendo este o máximo para que não haja prejuízo sobre o consumo voluntário da forragem (Noller et al., 1996). Assim, o elevado teor de parede celular na forragem poderia ter prejudicado o consumo voluntário e, consequentemente, o desempenho animal (Tabela 1).

Os teores de PB da forragem, durante todo o período experimental, estiveram abaixo do valor mí-
Tabela 3 - Teores de matéria orgânica (MO), proteína bruta (PB), proteína bruta digestível (PBD), fibra em detergente neutro (FDN) e fibra em detergente ácido (FDA) da forragem total e da fração folha + colmo (\%/MS)

Table 3 - Levels of organic matter $(O M)$, crude protein $(C P)$, digestible crude protein(DCP), neutral detergent fiber (NDF) and acid detergent fiber ( $A D F)$ of the total forage and leaf + steam fraction (\%/DM)

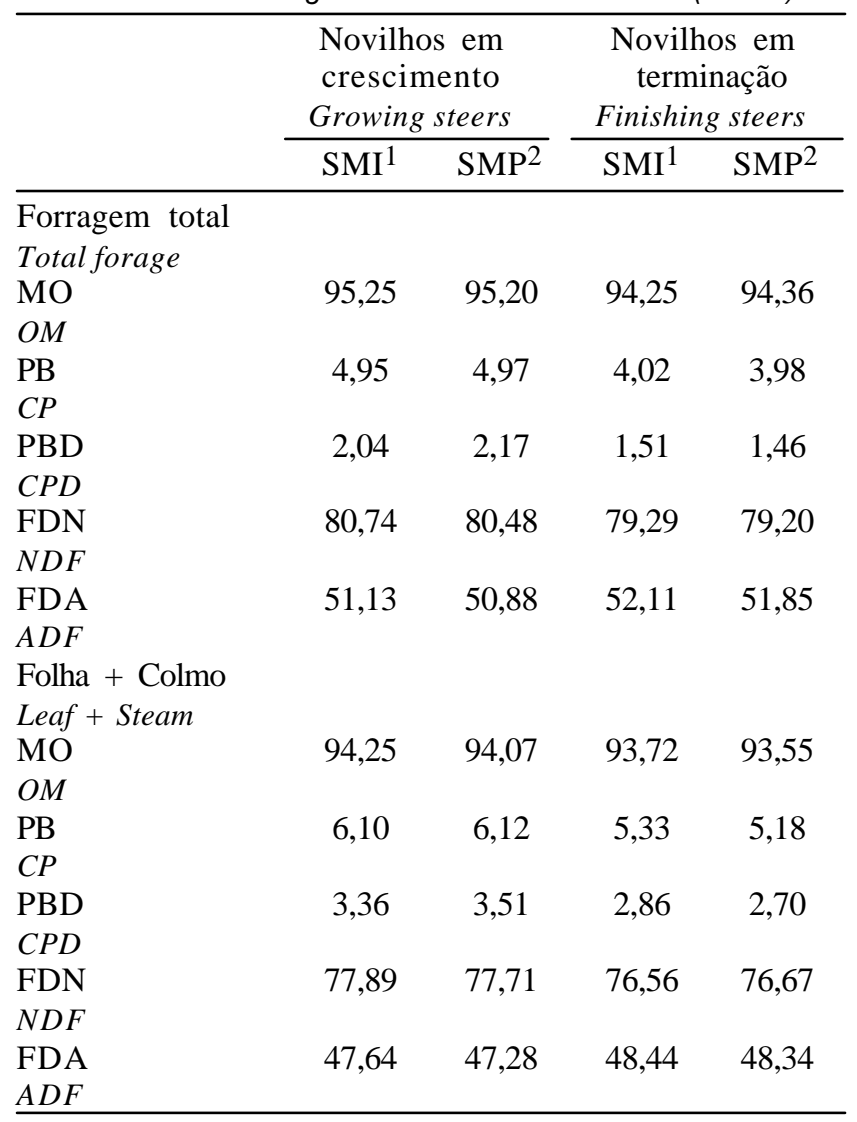

${ }^{1} \mathrm{SMI}$ : sal mineral; ${ }^{2} \mathrm{SMP}$ : sal mineral proteinado.

1 SMI: mineral salt; ${ }^{2}$ SMP: protein mineral salt.

nimo de 7\% na MS preconizado por Van Soest (1994) para que não haja prejuízo da utilização da forragem por parte dos microrganismos ruminais. Além dos teores de PB estarem abaixo dos níveis mínimos, a maior parte $(60 \%)$ deste nitrogênio estava na forma não disponível para os microrganismos (nitrogênio insolúvel em detergente ácido - NIDA), o que reduziria ainda mais os teores de nitrogênio que seriam aproveitados pelos microrganismos do rúmen. Os altos teores de FDN, FDA e NIDA são decorrentes da maturidade da planta que aumenta o conteúdo de parede celular, como hemicelulose, celulose e lignina (Reis et al., 1997).

Da mesma forma, os teores de PB da matéria verde seca, ou seja, das frações folha + colmo, foram 
semelhantes entre tratamentos e inferiores a 7\%/MS, embora uma fração inferior da forragem total estivesse na forma de NIDA (45\%/MS). Desta forma, mesmo que houvesse pastejo seletivo, por parte dos animais, evitando o consumo de material morto, o teor de PB do material ingerido também seria inferior ao mínimo (7\%/MS) estabelecido para que não haja prejuízo à fermentação ruminal.

O objetivo maior de suplementar o sal mineral associado a uma fonte protéica é de aumentar a disponibilidade de nitrogênio para que haja uma maior disponibilidade de amônia ruminal para o desenvolvimento dos microrganismos. Desta forma, o baixo teor de PB na forragem seria suprido pelo sal mineral proteinado e, assim, capaz de melhorar o desempenho animal. No entanto, o baixo consumo do suplemento (Tabela 1) possivelmente não porporcionou o mínimo de proteína degradável no rúmen para que não houvesse prejuízo à fermentação ruminal. Desta forma, seria necessária uma suplementação protéica em níveis mais elevados para que pudesse trazer resultados positivos sobre o desempenho animal.

A digestibilidade in vitro da matéria seca(DIVMS) foi semelhante para os tratamentos SMI e SMP (Tabela 4). Os valores obtidos para a DIVMS foram baixos. Isto possivelmente seja decorrente do período analisado (período do inverno). Assis (1997) observou DIVMS de $62 \%$ para a grama estrela roxa no verão. No inverno, o crescimento da forragem diminui e ocorre acúmulo de material morto. Conforme aumenta a maturidade da planta, o conteúdo de parede celular, principalmente a lignina, aumenta, resultando em redução da digestibilidade da forragem (Dove, 1998).

A relação entre o teor de NDT e PB da pastagem foi superior a 7 (Tabela 4). Moore et al. (1999) enfatizaram que, quando esta relação estivesse acima de 7, estaria havendo deficiência de proteína em relação à energia. Nestes casos, pequenas quantidades de proteína poderiam possibilitar aumento na ingestão de forragem e, conseqüentemente, melhoria no desempenho animal. Entretanto, para as condições deste experimento, não foi observada diferença no desempenho para animais suplementados com sal mineral proteinado, apesar da relação entre o NDT e a PB da forragem estar acima do valor 7. Possivelmente, o baixo consumo do suplemento aliado à baixa qualidade nutricional da forragem não possibilitaram que a dieta atingisse o mínimo de 7\% de PB/MS, determinando assim o baixo desempenho animal e a ausência de efeito da suplementação com sal mineral proteinado,
Tabela 4 - Digestibilidade in vitro da matéria seca (DIVMS), nutrientes digestíveis totais (NDT) e relação entre o NDT e a proteína bruta da forragem

Table 4 - In vitro dry matter digestibility (IVDMD), total digestive nutrients (TDN) and relationship between $T D N$ and $C P$ of forage

\begin{tabular}{|c|c|c|c|c|}
\hline & \multicolumn{2}{|c|}{$\begin{array}{l}\text { Novilhos em } \\
\text { crescimento } \\
\text { Growing steers }\end{array}$} & \multicolumn{2}{|c|}{$\begin{array}{c}\text { Novilhos em } \\
\text { terminação } \\
\text { Finishing steers }\end{array}$} \\
\hline & $\mathrm{SMI}^{1}$ & $\overline{\mathrm{SMP}^{2}}$ & $\mathrm{SMI}^{1}$ & $\mathrm{SMP}^{2}$ \\
\hline DIVMS & & & & \\
\hline $\begin{array}{l}\text { IVDMD } \\
\text { NDT }\end{array}$ & 42,71 & 44,13 & 44,03 & 43,59 \\
\hline TDN & 43,41 & 44,88 & 44,77 & 44,32 \\
\hline $\begin{array}{l}\text { NDT:PB } \\
T D N \cdot C P\end{array}$ & 877 & 903 & 1114 & 1113 \\
\hline
\end{tabular}

1 SMI: sal mineral; ${ }^{2}$ SMP: sal mineral proteinado.

${ }^{1}$ SMI: mineral salt; ${ }^{2}$ SMP: protein mineral salt.

quando comparado com a suplementação mineral.

\section{Conclusões}

O nível de suplementação com sal mineral proteinado $(0,07 \%$ do peso vivo), no inverno, em pastagem de grama estrela roxa, não proporcionou melhor desempenho animal, quando comparado ao sal mineral.

Durante o período avaliado, a forragem apresentou pequeno valor nutritivo, com níveis de PB inferiores a $7 \%$ e FDA acima de $40 \%$, o que resultou no baixo ganho de peso obtido no período.

\section{Literatura Citada}

ASSIS, M.A. Digestibilidade in vitro, degradabilidade in situ e composição química de gramíneas do gênero Cynodon submetidas ou não a adubação nitrogenada. Maringá: Universidade Estadual de Maringá, 1997. 48 p. Dissertação (Mestrado em Zootecnia) - Universidade Estadual de Maringá, 1997.

CECATO, U.; SARTI, L.L.; SAKAGUTI,E.S. et al. Avaliação de cultivares e linhagens de aveia (Avenna spp.). Acta Scientiarum, v.20, n.3, p.347-354, 1998.

DOVE, H. The ruminant, the rumen and the pasture resource: nutrient interactions in the grazing animal. In: HODGSON, J.; ILLIUS, A.W. (Eds.) The ecology and management in grazing systems. 2.ed. London: $\mathrm{CAB}$ International, 1998. 466p.

EUCLIDES, V.P.B.; EUCLIDES FILHO, K.E.; ARRUDA, Z.J. et al. Desempenho de novilhos em pastagem de Brachiaria decumbens submetidos a diferentes regimes alimentares. Revista Brasileira Zootecnia, v.27, n.2, p.246-254, 1998.

EUCLIDES, V.P.B.; EUCLIDES FILHO, K.; COSTA, F.P. et al. Desempenho de novilhos F1s angus-nelore em pastagens de 
Brachiaria decumbens submetidos a diferentes regimes alimentares. Revista Brasileira Zootecnia, v. 30, n. 2, p. 470481, 2001.

FNP - Anuário da pecuária brasileira. São Paulo: ANUALPEC, 2001. 359p.

GRANDINI, D.V. 2001. Produção de bovinos a pasto com suplementos protéicos e/ou energéticos. In: REUNIÃO ANUAL DA SOCIEDADE BRASILEIRA DE ZOOTECNIA, 38., 2001, Piracicaba. Anais... Piracicaba: Fundação de Estudos Agrários "Luiz de Queiroz”, 2001. p.235-245.

HELDT, J.S.; COCHRAN, R.C.; STOKKA, G.L. et al. Effects of different supplemental sugars and starch fed in combination with degradable intake protein on low-quality forage use by beef steers. Journal of Animal Science, v.77, n.10, p.27932802, 1999.

HOLDEN, L.A. Comparison of methods of in vitro dry matter digestibility for ten feeds. Journal of Dairy Science, v.82, n.8, p.1791-1794, 1999.

HOLDERBAUN, J.F.; SOLLENBERG, K.H. Canopy structure and nutritive value of limpograss pastures during mid-summer to early autumn. Agronomy Journal, v.84, n.1, p.11-16, 1992.

MINSON, D.J. Forage in ruminant nutrition. San Diego: Academic Press, 1990. 483p.

MOORE, J.E.; BRANT, M.H.; KUNKLE, W.E. et al. Effects of supplementation on voluntary forage intake, diet digestibility, and animal performance. Journal of Animal Science, v.77, suppl. 2/J, p.122-135, 1999.

MORAES, A.; LUSTOSA, S.B.C. Forrageiras de inverno como alternativas na alimentação animal em períodos críticos. In: SIMPÓSIO SOBRE NUTRIÇÃO DE BOVINOS, 7., 1999, Piracicaba. Anais... Piracicaba: Fundação de Estudos Agrários "Luiz de Queiroz", 1999. p.147-166.

MORAIS, J.P.G. Silagem de gramíneas tropicais. In: SIMPÓSIO SOBRE NUTRIÇÃO DE BOVINOS, 7., 1999, Piracicaba. Anais... Piracicaba: Fundação de Estudos Agrários "Luiz de Queiroz", 1999. p.7-26.

NOLLER, C.H.; NASCIMENTO Jr., D.; QUEIROZ, D.S. Exigências nutricionais de animais em pastejo. In: PEIXOTO, A.M.; MOURA, J.C.; FARIA, V.P. (Eds.) Produção de bovinos a pasto. Piracicaba: Fundação de Estudos Agrários "Luiz de Queiroz", 1997. p.319-352.

MOREIRA, F.B.; PRADO, I.N.; NASCIMENTO, W.G. et al. Níveis de suplementação de sal proteinado para bovinos nelore terminados a pasto no período do inverno. In: REUNIÃO ANUAL DA SOCIEDADE BRASILEIRA DE ZOOTECNIA, 38., 2001, Piracicaba. Anais... Piracicaba: Sociedade Brasileira de Zootecnia, 2001. p.923-924.

MOREIRA, F.B.; CECATO U.; PRADO, I.N. et al. Avaliação de aveia preta $c v$ Iapar61 Submetida a níveis crescentes de nitrogênio em área proveniente de cultura de soja. Acta Scienciarum, v.23, n.4, 2001b, p.815-821.

NATIONAL RESEARCH COUNCIL - NRC. Nutrient requirement of beef cattle. 7.ed. Washington, D.C.: 1996.
$242 \mathrm{p}$.

NUSSIO, L.G.; CAMPOS, F.P.; MANZANO, R.P. Volumosos suplementares na produção de bovinos de corte em pastagens. p.253-275. In: REUNIÃO ANUAL DA SOCIEDADE BRASILEIRA DE ZOOTECNIA, 38., 2001, Piracicaba. Anais... Piracicaba: Fundação de Estudos Agrários "Luiz de Queiroz", 2001.p.253-275.

REIS, R.A.; RODRIGUES, L.R.A.; PEREIRA, J.R.A. A suplementação como estratégia de manejo de pastagem. In: PEIXOTO, A.M.; MOURA, J.C. e FARIA, V.P. (Ed.) Produção de bovinos a pasto. Piracicaba: Fundação de Estudos Agrários “Luiz de Queiroz”, 1997. p.123-150.

SECRETARIA DA AGRICULTURA E DO ABASTECIMENTO - SEAB. Manual técnico do subprograma de manejo e conservação do solo. Curitiba, PR: 1994.372 p.

SILVA, D.J. Análise de alimentos (métodos químicos e biológicos). 2.ed. Viçosa, MG: Universidade Federal de Viçosa. 1990. $165 \mathrm{p}$.

SNIFFEN, C.J.; O'CONNOR, J.D.; VAN SOEST, P.J. et al. A net carbohydrate and protein system for evaluating cattle diets: II. Carbohydrate and protein availability. Journal of Animal Science, v.70, n.12, p.3562-3577, 1992.

TILLEY, J.M.A. \& TERRY, R.A. A two-stage technique for the in vitro digestion of forage crops Journal British of Grassland Society, v. 18, p. 104-111, 1963.

UNIVERSIDADE FEDERAL DE VIÇOSA - UFV. SAEG Sistema para análises estatísticas e genéticas. Versão 7.1. Viçosa: MG, 1997. 150 p. (Manual do usuário).

VALADARES FILHO, S.C. Nutrição, avaliação de alimentos e tabelas de composição de alimentos para bovinos. In: REUNIÃO ANUAL DA SOCIEDADE BRASILEIRA DE ZOOTECNIA, 37., 2000, Viçosa, MG. Anais... Viçosa: Sociedade Brasileira de Zootecnia, 2000. p.267-339.

VAN SOEST, P.J.Nutritional ecology of the ruminant.2ed. New York: Cornell University Press, 1994. 476 p.

ZANETTI, M.A.; RESENDE, J.M.L.; SCHALCH, F. et al. Desempenho de novilhos consumindo suplemento mineral proteinado convencional ou com uréia. Revista Brasileira Zootecnia, v.29, n.3, p.935-939, 2000. 